\title{
MASCULINIDADES À FLOR DA PELE: REFLEXÕES EM TORNO DE O CORAÇÃO DOS HOMENS, DE HUGO GONÇALVES
}

\author{
MASCULINITIES UNDER THE SKIN: \\ REFLECTIONS AROUND \\ O CORAÇÃO DOS HOMENS, \\ BY HUGO GONÇALVES
}

Jorge Vicente Valentim ${ }^{1}$

\section{RESUMO}

O artigo tem como objetivo apresentar algumas reflexões em torno do romance $O$ coração dos homens (2006), do escritor português Hugo Gonçalves, a partir da articulação dos conceitos de "masculinidade hegemônica" (CONNELL, 1995/2005) e "práticas da masculinidade" (ALMEIDA, 1996/2000) com aspectos inseridos na efabulação romanesca. Em um cenário distópico, onde as mulheres são banidas, os homens disputam entre si a sobrevivência e a permanência em um mundo conturbado e violento.

PALAVRAS-CHAVE: Masculinidades. Violência. Ficção portuguesa contemporânea. Hugo Gonçalves.

\section{ABSTRACT}

This article aims to present some reflections on the novel O Coração dos Homens (2006), by the Portuguese writer Hugo Gonçalves, based on the articulation of the concepts of "hegemonic masculinity" (CONNELL 1995/2005) and "masculinity practices" (ALMEIDA, 1996/2000) with aspects inserted in the novelistic plot. In a dystopian scenario, where women are banned, men compete with each other for their survival and permanence in a troubled and violent world.

KEYWORDS: Masculinities. Violence. Contemporary portuguese fiction. Hugo Gonçalves. 
Esse texto é para Mário César Lugarinho, amigo de longa data. Professor e pesquisador generoso, seus estudos vêm servindo de motivação para muitas de minhas inquietações. Citá-lo, aqui, é uma forma sincera de agradecer a sua presença inspiradora entre nós.

A masculinidade é um processo construído, frágil, vigiado, como forma de ascendência social que pretende ser. Miguel Vale de Almeida. Senhores de si.

O coração reage a cada toque. O pânico dos batimentos alastra-se pelo sistema circulatório, rebenta dentro da barriga e Ele descobre, mesmo depois de o telefone se calar, que dentro do corpo ainda pulsa o medo dos adultos.

Hugo Gonçalves. O coração dos homens.

Falar de masculinidades e, ao mesmo tempo, debater questões sobre sexualidades não constituem gestos inéditos e incomuns no cenário acadêmico atual. Felizmente. Apesar das dificuldades em se perceber um quantitativo menor nas abordagens específicas sobre as masculinidades no campo dos estudos literários (ainda mais se comparados aos trabalhos sobre questões de gênero em que a escritura feminina e os estudos feministas se sobressaem), tal como apontado por Luiz Carlos Santos Simon (2016), não se poderá negar que, na esteira dos men's studies - surgidos nos EUA, na década de 1970, sobretudo, a partir dos estudos pioneiros de Joseph Pleck (AMANCIO, 2010b) e amplamente alargados, graças aos ensaios incontornáveis da socióloga australiana R. W. Connell (1995/2005) -, outras abordagens começam a circular, sobretudo, no tocante às pesquisas voltadas para as literaturas de língua portuguesa, eixo principal do presente dossier.

Pode-se afirmar, inclusive, que tais propostas de análise vêm ocupando as pautas investigativas de forma muito mais significativa e assertiva a partir dos anos 2000. Cabe-me lembrar, no entanto, que, no campo das Ciências Sociais em Portugal, os trabalhos de Lígia Amâncio (1994/2010a) e Miguel Vale de Almeida (1996/2000) já despontavam na década de 1990, abrindo um espaço importante para as futuras discussões sobre as masculinidades e suas possíveis ligações com diferentes universos literários de língua portuguesa.

No cenário atual, para além dos textos já mencionados, é preciso destacar duas contribuições importantes sobre o exame das masculinidades no campo dos estudos literários lusófonos. A primeira é de Mário César Lugarinho (2013) que, em um cuidadoso e provocativo ensaio, elucida as relações entre as masculinidades e o processo colonizador português nos antigos territórios ultramarinos, analisando os mecanismos discursivos do Estado Novo Salazarista e sua máxima do "homem novo", enquanto instrumento articulado para tentar garantir o sucesso da ocupação colonialista. Em uma 
perspectiva interseccionista, ao cruzar os conceitos de gênero, raça e classe social, Lugarinho ainda investiga os alicerces sustentadores da orquestração daquela virilidade inquestionável do "homem novo" português e vasculha as teias falaciosas dos seus discursos. E a segunda é do professor e ensaísta português António Fernando Cascais (2019), que investe um olhar crítico muito perspicaz e coerente na produção literária portuguesa sobre a guerra colonial, desvendando as armadilhas e as falácias de uma masculinidade hegemônica que tenta se sobrepor às demais, a partir das efabulações de autores e obras conhecidos, além de outros fora da rede de acesso. O ponto importante a ser destacado nesse estudo é a forma como o autor privilegia uma produção não apologética dos confrontos bélicos de libertação em territórios africanos, a fim de desfetichizar a bagagem imagética vinculada ao paradigma incorruptível dos "barões assinalados" (CAMÕES, 2011, p. 71).

Ora, no fundo, não estamos distantes do pensamento de Raewin Connell (2005), quando chama a atenção para a capilaridade do conceito de "masculinidades" e para a sua utilização não no singular, mas no plural (masculinities), envolvendo diferentes papéis de atuação na esfera social. Assim, de uma forma geral, compreendida na sua multiplicidade, as masculinidades podem ser englobadas, dentro de atuações diretas nas estruturas social, política e econômica, denominadas por ela como: "masculinidade hegemônica" (CONNELL, 2005, p. 76), porque definida como uma "configuração da prática de gênero que encarna a resposta atualmente aceita ao problema da legitimidade do patriarcado, na qual garante a posição dominante dos homens e a subordinada das mulheres" (CONNELL, 2005, p. 77); "masculinidade subordinada" (CONNELL, 2005, p. 78) - ainda que, particularmente, prefira a expressão masculinidade subalterna, em virtude de sua forte concatenação ao papel passivo de dominado sobre o qual a masculinidade hegemônica se impõe -, dirigida, em especial, aos homossexuais, identificados por Connell como alvos preferidos de um conjunto de práticas materializadas, tais como exclusões político-sociais, abusos e violências das mais diversas ordens e discriminações; "masculinidade cúmplice" (CONNELL, 2005, p. 79), posto que seus agentes se beneficiam das comodidades possíveis dentro de um padrão de comportamento estandardizado, sujeitando-se de igual modo à "subordinação total da mulher" (CONNELL, 2005, p. 79); e a "masculinidade marginalizada" (CONNELL, 2005, p. 80), emergida a partir da intersecção de gênero, raça e classe, reiterando que as masculinidades oriundas das classes média e trabalhadora são constantemente reformuladas dentro de uma "dinâmica social em que as relações entre classe e gênero estão simultaneamente em jogo" (CONNELL, 2005, p. 80)².

Como se pode observar, o contributo da investigadora australiana sobre a dimensão plurissignificativa do conceito reside na sua não exclusão das esferas investigativas sobre gênero, já que as masculinidades podem ser compreendidas como, “[...] simultaneamente, um lugar nas relações de gênero, as práticas através das quais homens e mulheres envolvem esse lugar no gênero e os efeitos dessas práticas nas experiências corporais, de 
personalidade e da cultura" (CONNELL, 2005, p. 71). Na verdade, o seu perfilhamento impulsiona gestos de leitura de sujeitos masculinos marcados pela fragmentaridade, pela não-uniformidade, pela não-compacidade, mas que necessitam explorar os limites possíveis de suas atuações, a ponto de podermos falar, também, de masculinidades à flor da pele, porque exacerbam as suas manifestações, bem como de "práticas da masculinidade" (ALMEIDA, 2000, p. 19), ao desempenharem diferentes ações físicas e discursivas.

Imaginemos, agora, o seguinte enredo: um espaço nominado apenas como Cidade, figurado como um Estado-Nação autônomo e independente, resolve expulsar todas as mulheres, com a tese de que elas provocam um enfraquecimento da e na raça humana, em virtude da sua capacidade de expressão de sentimentos e emoções. Assim, tal como informa o narrador, elas são banidas da Cidade porque "impedem a masculinidade dos homens, enfraquecem-nos e danificam os filhos com seus cuidados. Têm defeitos genéticos, os músculos magros, falta de coragem, praticam o carinho e o excesso de atenção. No desfile, o choro de algumas é outro sintoma da sua debilidade" (GONÇALVES, 2006, p. 21).

Por isso, todas elas são expulsas. As que conseguem escapar cruzam a fronteira para um outro país, designado como Estrangeiro, onde podem circular livremente, constituir família, trabalhar, votar, amar e transitar sem ter de dar explicações ou pedir autorização para uma figura masculina tutelar. As que não têm sucesso na saída são colocadas dentro dos "Edifícios da periferia da Cidade. Lugares que albergam a solução para os impulsos sexuais" (GONÇALVES, 2006, p. 53). Sem qualquer tipo de contato íntimo ou manifestação de afetividade, essas mulheres "são obrigadas, por lei, a foder com qualquer homem” (GONÇALVES, 2006, p. 53), sendo utilizadas exclusivamente para a satisfação sexual dos habitantes da Cidade. A administração local é tão cuidadosa na frequência periódica dos seus cidadãos, que, na observância rigorosa de "nunca estar com a mesma mulher em um período de seis meses de forma a não estabelecer relações afectivas" (GONÇALVES, 2006, p. 54), exerce uma vigilância para evitar a repetição de usuários com a mesma "mercadoria", tal como são designadas. Afinal, como bem esclarece o narrador: "Elas são números. Eles não dizem o nome" (GONÇALVES, 2006, p. 54).

Nesse ambiente, marcado por uma profunda homossociabilidade ${ }^{3}$ e onde a heteronormatividade é a regra incontestável, não apenas as mulheres, mas os homossexuais constituem uma camada da população que precisa ser expurgada e eliminada, não sem antes passar por uma imolação pública. Toda a vida social passa a ser regida, portanto, por um código de violência, onde a lei do mais forte impera e acaba por dividir toda a massa populacional masculina em duas camadas: a dos dominadores e a dos dominados. A alimentação desse comportamento bipolarizado ocorre de forma pedagógica, dentro do espaço das escolas, onde o esporte escolhido para perpetrar a brutalidade sobre o mais fraco destila a maneira de como os mais fortes podem e devem castigar todos aqueles que rasuram a ordem hegemônica: o pugilismo. 
É, portanto, com os próprios punhos que a Cidade impõe o seu senso de justiça e de castigo sobre os diferentes, eliminando assim qualquer possibilidade de manifestação das diversidades sexuais, seja as femininas, seja outras masculinas, como a homossexualidade:

Dois frequentadores do ginásio são empurrados pelo grupo contra a parede e pontapeados nas costas. Foram encontrados nus, erectos, tocando-se, marcas de bocas na pele. Este é o pior crime, a efeminização, a destruição da identidade masculina, o nojo. Porque as pulsões sexuais, glorificadas e estimuladas, têm soluções conhecidas por todos, de fácil acesso, mas nunca outro macho, uma aberração, homens penetrados como se fossem mulheres (GONÇALVES, 2006, p. 51-52).

Tal como a cena descreve, a diferença precisa ser exterminada para não abalar os alicerces da masculinidade hegemônica e heterocentrada, defendida no espaço da Cidade. Na verdade, a exposição pública da homossexualidade alheia e a sua adjetivação efeminizadora dissecam uma homofobia latente, porque "situa e exorciza o perigo homossexual da homossocialidade" (ALMEIDA, 2000, p. 68). Essa, por sua vez, é compreendida pelos atores masculinos da Cidade como uma força que evita qualquer tipo de diversidade desestabilizadora da ordem heteronormativa. Nessa esfera, as relações sexuais e físicas constituem um jogo embrutecido com regras bem definidas, onde, por um lado, é preciso expurgar os dois rapazes homossexuais descobertos na sua intimidade, e, por outro, os "homens têm de subjugar as mulheres, impor-lhes a anatomia masculina, penetrá-las, pensar apenas no seu próprio prazer, correr par o orgasmo, ejacular quando quiserem, onde escolherem" (GONÇALVES, 2006, p. 54). Ou seja, as masculinidades hegemônicas se sobrepõem às masculinidades subalternas e às feminilidades.

Ligia Amâncio adverte que "os discursos homofóbicos estão frequentemente presentes nos rituais performativos da masculinidade hegemônica e podem assumir formas particularmente perversas" (AMANCIO, 2010b, p. 106). No romance $O$ coração dos homens (2006), a rejeição às outras formas de manifestação afetiva e desejante, a necessidade de visualização pública do expurgo das dissidências, como forma de controle das mentalidades e dos corpos, e a manipulação dos habitantes da Cidade, desde a mais tenra idade, para a continuidade da rede de brutalidade, violência e extermínio acabam concretizando essa mesma rede de práticas perversas: “[...] o corpo como único meio para o domínio masculino, e a loucura coreografada, gestos contundentes disparados com graciosidade, toda essa violência submetida ao estilo, a beleza quando se magoa" (GONÇALVES, 2006, p. 51).

Como já se pode perceber, esse é o motivo central do romance em análise, do escritor português Hugo Gonçalves. Toda a sua efabulação baseia-se na expressão vívida de corpos masculinos que necessitam exercitar mecanismos de poder a partir do domínio sobre o outro pela violência e pela imposição da força. Em um universo com tonalidades distópicas e apocalípticas - não à toa, posteriormente, a Cidade mudará de liderança 
política e esta ingressará numa guerra de onde sairá vencida e completamente destruída -, a narrativa vai sendo tecida como uma espécie de Bildungsroman, na medida em que as trajetórias de três jovens vão sendo construídas, desde sua formação escolar, com "seu[s] desejo[s] de aperfeiçoamento como indivíduo[s], mas também como classe" (MAAS, 2000, p. 13), dentro da lógica convencionada pelos discursos da Cidade, até a fase adulta de amadurecimento de cada um deles, revelando as alterações tanto no seu modus vivendi quanto no seu modus operandi, e os diferentes caminhos trilhados individualmente.

Nesse contexto, a trama centra-se na trajetória de três personagens: Ele, Mau e Grande, cujas nomeações já comprovam a rejeição dos vínculos coletivos (familiares, na ausência dos seus sobrenomes) e individuais (com a apresentação a partir de nomes civis genéricos). Essa desvinculação de qualquer meio expressivo de afetividades surge também partilhada pelo próprio narrador, posto que, conforme observado nas citações anteriores, emprega preferencialmente orações coordenadas assindéticas, valendo-se de advérbios, pronomes e conjunções apenas em casos necessários, bem como de outras estruturas sintáticas, como as subordinadas, numa quantidade menor. Essa secura no modo de narrar parece indicar que a voz responsável pelas revelações e pelos passos da trama ficcional compactua também com esta sociedade sem cargas afetivo-emocionais, prezando apenas pela objetividade e pela neutralidade na observação dos fatos experienciados. Chamo à atenção, no entanto, para esse dado, porque, como se verá adiante, esse recurso constitui um blefe.

$\mathrm{Na}$ verdade, trata-se de uma artimanha discursiva muito bem engendrada, exatamente porque deixa mais flagrante as dissonâncias desse espaço. Verifica-se, portanto, que a masculinidade hegemônica da Cidade necessita de mecanismos impositivos da ordem a partir de gestos carregados de brutalidades, realçando-a como um "modelo cultural ideal", muito próximo daqueles efeitos colaterais descritos por Miguel Vale de Almeida, pois "exerce sobre todos os homens um efeito controlador, através da incorporação, da ritualização das práticas da sociabilidade quotidiana e de uma discursividade que exclui todo um campo emotivo considerado feminino" (ALMEIDA, 2000, p. 17).

Assim, do "perseguir outros miúdos" na escola e no ginásio a "procurar o risco e precisar do perigo" (GONÇALVES, 2006, p. 33) em aventuras obscuras no espaço urbano; das descobertas das "possibilidades do seu órgão sexual" à troca de sugestões entre os amigos sobre "truques para intensificar o prazer" (GONÇALVES, 2006, p. 43); da percepção da funcionalidade dos combates, enquanto "exercícios dramáticos, histórias" para "Dominar outro homem. Decidir um conflito com as habilidades motoras" (GONÇALVES, 2006, p. 50), à confirmação do seu status enquanto "atletas profissionais, agentes do poder da Cidade que se preparam para confirmar a superioridade dos machos" (GONÇALVES, 2006, p. 77); Ele, Mau e Grande concluem a 
fase escolar e, em seguida, partem para o Estrangeiro como representantes esportivos da Cidade e confrontam-se, finalmente, com uma realidade completamente diferente da vivida no seu local de origem.

Ali, decidem abandonar a competição e pedir asilo político, mentindo sobre a sua condição na Cidade. A estratégia dos líderes da delegação de deixar os atletas em livre trânsito pelo Estrangeiro, com o objetivo de que eles "percebam a deficiência de um país com homens que se casam com outros homens, com mulheres que aplicam e usam as leis, com crianças educadas por empregadas domésticas" (GONÇALVES, 2006, p. 79), acaba por alimentar os planos dos jovens de abandono definitivo da Cidade, mas não porque Ele, Mau e Grande sejam tomados e arrebatados por um profundo sentimento de mudança e de consciência do seu estado de autoalienação aniquiladora. A ideia surge como uma aventura de imposição do modus vivendi operacionalizado na Cidade, como uma exacerbação dos gestos descomedidos, agora aplicados no espaço do Estrangeiro. Ao vislumbrar a terra desconhecida, como uma espécie de locus que precisa ser desbravado e ocupado, Ele, Mau e Grande parecem assumir o papel de novos colonizadores:

No estrangeiro, os amigos foram examinados por médicos. Continuaram a simular episódios de intolerância no seu passado. Elogiaram a liberdade de opinião dos habitantes do Estrangeiro. Tudo mentira. Eles querem apenas um novo lugar para o prazer, mulheres durante a noite, nenhuma disciplina de horários, a preguiça esticada num sofá, mais programas de televisão, iniciar as mais longas férias de sempre (GONÇALVES, 2006, p. 86).

Ora, no meu entender, é significativo o papel desempenhado pelos três jovens ao burlarem as normas de solicitação de refúgio político. Longe de se constituir em um puro gesto de consciência da dominação operacionalizada na Cidade, da qual eles também são vítimas, nesse novo local, não deixam eles de performatizar um papel muito parecido com aqueles modelos de masculinidade hegemônica, vigorada pelo viés do "homem novo". Ele, Mau e Grande não almejam abandonar a práxis da violência física enquanto forma de imposição de suas identidades, antes intentam "testar a cobardia dos habitantes desse país” (GONÇALVES, 2006, p. 79) com um repertório que, se não inclui a reverberação de um planejamento de ocupação nacional, tal como prescrevia o padrão colonizante do "homem novo", ao menos, os três jovens mantêm viva aquela mesma pressuposição de "condição de superioridade frente aos povos dominados” (LUGARINHO, 2013, p. 19).

Ou seja, trata-se de uma estratégia política de permanência dos velhos hábitos, a fim de, com eles, estenderem a rede hierárquica em que eles desempenhariam o papel de domínio absoluto e os habitantes do Estrangeiro o de subjugados. No entanto, é aí que essa artimanha colonizadora falha, porque eles acabam sendo inseridos em diferentes ambientes familiares, onde convivem com expressões de afeto e de familiaridade nunca antes experimentados. 
Mau e Grande até tentam, de certo modo, aderir e adaptar-se a novos comportamentos, no entanto, cedo constatam a inaptidão para um tipo de vida muito mais pacífico e ordenado. Por sua vez, Ele passa por diferentes processos porque não aceita renunciar a sua condição de homem dominador e mantenedor do seu status pela violência. Não à toa, ao entrar num lar onde conhece a sua "mãe temporária" (GONÇALVES, 2006, p. 88) e Maria 1, espécie de irmã postiça, com quem terá uma breve relação amorosa, Ele continua na prática do pugilismo, tornando-se, inclusive, um atleta reconhecido nos meios midiáticos. No entanto, ao sofrer um empate em uma disputa do cinturão e ver-se preterido ao título por causa das regras da competição, Ele afasta-se de todos e mantém-se isolado, buscando uma neutralidade diante de sentimentos desestabilizadores: "Ele quer voltar a combater, mas sem emoções. Ele quer transformar a violência em uma manifestação artística aplaudida por milhões de pessoas. Ele quer ser campeão" (GONÇALVES, 2006, p. 137). Focado em um pragmatismo alienante, só a vitória pela imposição da força e da violência interessa a Ele. E mesmo diante de uma possível segunda aventura amorosa, com Maria 2, mulher financeiramente independente e autônoma, com quem terá um breve e casual romance, Ele não abdica da sua forma de ser e estar no mundo, mesmo contrariando o modus vivendi do Estrangeiro, onde a liberdade de expressão social e afetiva constitui uma realidade inalienável.

No fundo, os três rapazes deslocam-se da Cidade para o Estrangeiro, mas o pensamento de dominação (colonizadora?) não os abandona. Um dos momentos mais flagrantes dessa permanência ocorre na entrevista com o professor universitário, interessado em pesquisar os hábitos da Cidade, quando este insiste em tocar numa possível ocorrência de abusos sexuais e familiares. A reação dos jovens é imediata. Sem chance para o diálogo, a única resposta viável é a violência física como instrumento de comprovação de uma masculinidade hegemônica que não aceita qualquer tipo de dúvida sobre sua condição:

$\mathrm{O}$ académico tentou passar a fronteira para fazer pesquisa, mas as autoridades masculinas, que apenas autorizam estrangeiros em negócios ou como espectadores de eventos desportivos, recusaram-no. Quando descobriu os três exilados entrevistou-os. [...] Quer informações sobre a violência de rua como forma de adquirir prestígio na Cidade, sobre a valorização da força muscular, sobre a impunidade dos cidadãos que fazem justiça com as próprias armas. Insiste em questões sobre sexo entre homens, a certeza de que na Cidade existem encontros homossexuais. Pergunta-lhes se foram abusados pelos familiares, pelos professores ou pelos vizinhos. Sugere que a Cidade é um lugar de depravação e de escravatura. Eles recusam as afirmações, explicam que a homossexualidade é punida com castigos físicos e que representa a efeminização dos genes masculinos.

Confessem, não tenham vergonha, a culpa não é vossa, assumam-se. 
Grande dá-lhe uma cabeçada no nariz, deslocando-lhe o osso. O professor cai sobre a mesa de trabalho. Mau agarra-o pelo cabelo, os outros pelos braços e pelas pernas. Balançam-no como se fosse um animal morto, fazendo-o atravessar a porta de vidro. No outro lado, num pátio com canteiros, estão os brinquedos dos filhos do professor. Uma tenda para crianças, algumas bonecas. [...]

Grande diz:

Se nos procurares, pegamos-te fogo.

Ele diz:

E endireita o nariz depressa. Se o osso calcifica, nunca mais volta ao lugar (GONÇALVES, 2006, p. 108-109; grifos meus).

Interessante observar que, no estudo antropológico e espacialmente localizado de Miguel Vale de Almeida, o ensaísta português sublinha que as relações entre os gêneros são marcadas como "relações de poder, assimetria e desigualdade, e não simplesmente relações simétricas e complementares, como o senso-comum gosta de pensar" (ALMEIDA, 2000, p. 15). Não me parece que as reações de Ele, Mau e Grande, acima descritas, estejam distantes dessa realidade, na medida em que a mesma recusa pela diversidade sexual, independente de como, onde e porque ocorra, pode ser observada nos espaços efabulados em $O$ coração dos homens. A rejeição vem à tona, com a imposição de masculinidades (hegemônicas) à flor da pele, seja pelo viés da misoginia, onde as mulheres são consideradas "como utensílios para a diversão, como copos de álcool, corridas de moto, lutas, invasões de propriedade ou um salto ruidoso, de uma varanda, para a serenidade de uma piscina" (GONÇALVES, 2006, p. 154), cabendo-lhes exclusivamente um papel de satisfação sexual e procriação, sem qualquer afinidade ou laços afetivos; seja pelo da homofobia interiorizada, onde "o medo da homossexualidade, dos homossexuais e da própria homossexualidade latente" os motiva a exorcizar "em formas de acção social que excluem, discriminam (e até atacam, fisicamente)" (ALMEIDA, 2000, p. 69) qualquer sinalização ou exposição dessa diferença, sobretudo, quando esta vem encarnada em masculinidades marginalizadas (CONNELL, 2005).

Talvez, por isso, a forma mais imediata de expressar essa necessidade de dominação sobre o outro resida na prática do pugilismo, do atacar, do socar, do machucar e do subjugar o outro em um espetáculo público de uma "luta desumanizada porque os sentimentos enfraquecem os homens" (GONÇALVES, 2006, p. 146). Aqui, ocorre uma interessante quebra da fronteira que separava os dois espaços. Se na Cidade havia um exercício contínuo de uma masculinidade hegemônica sobre as demais e sobre as mulheres, no Estrangeiro, onde essas transitam livremente e vivem dentro de um ambiente democrático e os indivíduos podem manifestar os seus desejos e as suas orientações sexuais sem medo, o sentimento de civilidade perde-se completamente quando o assunto é a luta entre dois homens dentro de um ringue: 
Toda a audiência contraria a civilização. Estas pessoas, que rezam antes de dormir, que sabem segurar os talheres, que oferecem dinheiro para organizações beneméritas e que amam os filhos, pagaram para assistir a uma luta, pediram a aniquilação de um atleta, celebraram a sua derrota e os castigos físicos. Como não podem ser protagonistas da violência nas suas vidas cheias de arrumação, de regras, de tolerância, fecham-se numa arena, cúmplices dos lutadores, mas sem nome, sem precisarem de se magoar. Na manhã seguinte, serão outra vez os cidadãos que adoram a inocência das crianças e que apagam a televisão se por acaso encontram estropiados de guerra (GONÇALVES, 2006, p. 149; grifos meus).

$\mathrm{Na}$ verdade, aquilo que para Ele representa a afirmação dominadora da sua masculinidade, para os moradores do Estrangeiro significa a possibilidade de exacerbar uma vontade de violar o outro, completamente camuflada pela máscara da civilidade que todos esses indivíduos de bem utilizam. Nesse sentido, não deixa Hugo Gonçalves de expor uma interrogação pontual e cirúrgica aos leitores: até que ponto a civilização se distancia da barbárie, mesmo quando esta se esconde sob os auspícios de uma competição esportiva? Serão os dois conjuntos de habitantes tão diferentes entre si, como as exposições desse narrador heterodiegético levam a crer? Não estarão essas masculinidades à flor da pele expondo a assimetria e a desigualdade nas relações sociais e de gênero?

Toda essa espetacularização da violência configura, de certo modo, aquilo que Miguel Vale de Almeida irá designar como "práticas da masculinidade" (ALMEIDA, 2000, p. 19), na medida em que os agentes incorporadores de uma masculinidade hegemônica (CONNELL, 2005) - no caso de $O$ coração dos homens, as três personagens centrais: Mau, Grande e, sobretudo, Ele - servem como instrumentos de catarse dos atores das masculinidades subordinadas e cúmplices (CONNELL, 2005), representadas pelos “cidadãos de bem" que se sentem confortáveis em seus lares, sem qualquer sentimento de arrependimento ou cumplicidade. Daí a reação de Ele ao entrar no ringue, porque, mais do que vencer a luta, é preciso oferecer um espetáculo aos consumidores e pagantes do auditório:

Mas Ele sabe que é preciso vencer continuamente, com brutalidade. Destruir, suprimir o adversário e correr o risco de provocar uma morte no ringue, oferecer aos espectadores o que eles procuram: imagens de sangue, estragos físicos, a pornografia, a carnificina, e o instrumento contra a ordem, o fim das regras que domesticavam os homens. Os espectadores querem experimentar, através dos pugilistas, todas as qualidades libertadoras da violência (GONÇALVES, 2006, p. 130).

A vitória de Ele sobre o campeão nacional, nesse novo confronto, confere-lhe fama, destaque e respeito. No entanto, a esperada fortuna só aparece misteriosamente pelas mãos de Grande, que surge com um saco cheio de dinheiro, sem uma explicação convincente: "Há gente com muito 
dinheiro. E não se fala mais nisso" (GONÇALVES, 2006, p. 153). De pronto, os três rapazes gastam com viagens, mulheres, consumo de drogas e bebidas alcóolicas, além de uma rotina de gestos de vandalismos e violências, sempre com a necessidade de demarcar uma rejeição sobre tudo aquilo que poderia diminuir a potência das suas masculinidades, além do descuido com o próprio bem-estar pessoal.

Somente no final da jornada, dois acontecimentos demarcam uma mudança radical na trajetória dos três jovens, sobretudo, na de Ele. O primeiro ocorre no final de uma das noites, quando eles se separam e decidem terminar a aventura de forma diferente. No seu quarto de hotel, Ele defronta-se com a realidade da Cidade, há muito deixada para trás, juntamente com seu pai e seus dois irmãos. Ao ligar a TV, toma conhecimento de que "aconteceu uma mudança de estratégia na nova geração de governantes da Cidade", em que seus líderes "já não querem apenas um lugar para praticar suas ideias, as suas pulsões, a sua biologia, mas ambicionam impor-se ao resto da humanidade, em toda a geografia do planeta" (GONÇALVES, 2006, p. 174).

O segundo acontecimento deflagrador da separação dos três amigos ocorre na véspera da luta de retorno aos ringues de Ele. Grande aparece com dois dedos decepados e um cadáver no bagageiro do carro. Somente aí, Ele e Mau dão conta de que o saco de dinheiro, que lhes proporcionou momentos de puro êxtase entre mulheres, bebidas, drogas e jogos de azar, não surgiu por acaso: "O dinheiro era dele? Grande embala a mão deficiente junto do peito: Isso não interessa. Nós gastámos tudo e nunca ninguém se empenhou em saber donde tinha aparecido aquele saco" (GONÇALVES, 2006, p. 186).

Confrontado diretamente, por um lado, com um projeto de conquista alargada dos líderes da Cidade, anunciada pelo telejornal, e, por outro, com um assassinato, com a descoberta de que o dinheiro gasto veio pelo sangue de um desconhecido, e somente com o pacto de amizade transformado em um vínculo de cumplicidade criminosa com a morte desse mesmo desconhecido, Ele vai se dando conta das mudanças de sua vida, do seu envelhecimento inevitável e da necessidade de transformar o estatismo em um dinamismo vital. Assim, a rede homossociável estabelecida entre Ele, Mau e Grande desfaz-se definitivamente e cada um segue um rumo diferente. Por conseguinte, a única forma que Ele encontra para extravasar essa nova etapa de vida é voltar às lutas e ao pugilismo. Por isso, busca mais uma vez um afastamento completo e evita qualquer motivo de alteração emocional, neutralizando as notícias da Cidade e dos amigos e absorvendo todas as atenções para uma nova luta, uma nova tentativa de retorno ao mundo da exposição dos corpos no ritmo brutal dos combates públicos. Isso efetivamente não acontece, porque cedo percebe as mudanças físicas sentidas pela passagem do tempo, pelo desgaste do álcool e das drogas, levando-o a abandonar essa nova luta no meio do assalto.

Gosto de pensar que, aqui, a narrativa aponta para uma derrota de Ele, como um sinal de que as hegemonias masculinas não permanecem ad aeternum. E o mesmo processo ocorre com a Cidade, espaço onde as masculinidades hegemônicas imperam e chegam a uma exacerbação dominadora, 
que impelem os seus líderes a um plano colonizador global: "Os governantes não se preocupam apenas, como os fundadores da Cidade-Estado, com a preservação de um território para o prazer, para a luta e para a afirmação da natureza dos homens" (GONÇALVES, 2006, p. 178).

Em uma estratégia bem urdida, Hugo Gonçalves esboça nesse cenário uma relação especular com antigos regimes totalitários que dizimaram a Europa, já que o império de masculinidades hegemônicas da Cidade sugere alguns reflexos e espectros do nazifascismo e da política de pureza da raça, onde todas as diferenças precisam ser exterminadas, sob o comando de seus governantes: "Querem determinar as leis de outros países, estabelecer a hegemonia masculina em todos os continentes, castigar aqueles que não obedecerem" (GONÇALVES, 2006, p. 179).

No entanto, tal como Ele, que desiste da luta diante de um oponente mais novo e percebe que "toda a satisfação é temporária" (GONÇALVES, 2006, p. 144), também essa vontade de dominação acaba sendo vencida, mas não sem a devastação do espaço da Cidade e a dizimação de muitos dos seus habitantes. Aos sobreviventes, resta a esperança do recomeço diante dos cacos deixados pelos conflitos armados e o reencontro com os familiares que fugiram para outros países. Assim se dá o reencontro de Ele com seu pai e seus dois irmãos, com os antigos locais de sua infância e com os amigos Mau e Grande.

Ora, mesmo diante daquilo que poderia ser uma oportunidade de redimensionar os comportamentos, o narrador prontamente revela que mais difícil do que desarmar as mãos é descolonizar os espíritos marcados por uma masculinidade hierarquizadora. Sem gestos de carinho ou de manifestação de sentimentos, o novo convívio entre Ele e seus familiares denuncia as relações assimétricas de gênero, dentro das próprias masculinidades que cada um deles representa: "Eles são homens que se mantêm na superfície dos sentimentos. Não choram, não se expõem, enrolam a dor e o medo, amarram tudo no interior das artérias. Não podem ficar em último" (GONÇALVES, 2006, p. 204).

Como, então, vislumbrar a possibilidade de um recomeço depois da derrota e da destruição? Mau termina seus dias como um vendedor de uma banca de jornais. Grande casa-se com Maria 1 e constitui uma família com ela, em um lugar onde, no passado, isso seria inimaginável. E, perante as situações de mudanças presenciadas, tal como esclarece o narrador, "Ele sente-se estrangeiro, um viajante de passagem” (GONÇALVES, 2006, p. 203).

Logo, a única forma encontrada por Ele para lidar com os deslocamentos e os estranhamentos e recuperar aquele mesmo espírito de quando a Cidade ainda era dominada pelas hierarquias masculinizantes é voltar, novamente, aos ringues. Na verdade, essa necessidade da exposição, do embate de corpos e da espetacularização da violência consiste no único dinamismo possível no modus vivendi da personagem. Toda a descrição final da última cena do romance, quando Ele, "atravessando o esplendor 
da insanidade, a comoção da violência, não consegue identificar nenhuma cara no público" (GONÇALVES, 2006, p. 226), estabelece uma ressonância com aquela mesma dificuldade de perceber as inevitáveis alterações que o tempo impõe. Ou, retomando aqui as palavras de Miguel Vale de Almeida, não será essa tentativa de retorno ao campo de batalha física um "sinal da dificuldade em aceitar mudanças no género" (ALMEIDA, 2000, p. 134) por parte do protagonista? Não será a sua neutralidade e impessoalidade uma maneira de impor, mais uma vez, uma polarização não só entre os gêneros, mas também entre os papéis sociais de dominador e dominado, enquanto "condição necessária à construção do sentido de masculinidade hegemônica" (AMANCIO, 2010b, p. 106), da qual Ele não quer se afastar?

Se esse pode ser um dos entendimentos da cena de entrada de Ele no ringue - e, por conseguinte, também, toda a narrativa de $O$ coração dos homens vem sendo tecida por um narrador que ostenta esse mesmo afastamento, quase que atestando uma idêntica impessoalidade, neutralidade e objetividade no ato de contar -, Hugo Gonçalves promove uma sensível alteração no final, provocando uma reflexão inevitável: será, realmente, a masculinidade hegemônica de Ele imutável e inegociável? Serão as lutas os únicos meios possíveis de Ele se manifestar e se comunicar como ser humano e como homem?

Tudo aquilo era tão lento, os braços alongavam-se, avançavam, e depois recuavam, devagar, os ombros fechavam-se, a cara protegida, os músculos transpirados.

Eu andei pelo corredor que acabava no ringue.

Todas as minhas memórias eram físicas. Eu apenas sabia sentir com a boca, com o sangue, com o estômago. Nesse momento, atravessando o esplendor da insanidade, a comoção da violência, não conseguia identificar nenhuma cara no público. Esses eram os instantes que antecediam a solidão e que cumpriam o obrigatório caminho da minha natureza.

Ele entrou no ringue.

Eu entrei no ringue (GONÇALVES, 2006, p. 229; grifos meus).

Ao reproduzir as mesmas sentenças do narrador heterodiegético, agora, contaminadas por uma interveniência autodiegética, com marcantes memórias físicas, há uma sensível sugestão de que, na verdade, toda aquela pretensa neutralidade buscada na articulação de um afastamento ao longo de todos os eventos relatados constitui uma grande e salutar falácia narrativa. Se a perspectiva em $3^{\text {a }}$ pessoa começa a se reapresentar a partir da $1^{\text {a }}$ - "Ele entrou no ringue. Eu entrei no ringue" (grifos meus) -, então, fico a me interrogar se todo o conteúdo narrado não constitui um insidioso blefe, a que o próprio narrador não consegue sustentar? Sendo assim, isto já não seria um sinal de que as masculinidades, na sua pluralidade, abarcam também um leque de mutações? Não será o assumir a autodiegese uma maneira não só de contestar aquela pretensa isenção e imparcialidade, mas também de 
assumir "o fim do sujeito universal” (AMANCIO, 2010b, p. 103), porque a integralidade não é suficiente para abranger o caráter móvel e provisório das masculinidades?

Vale relembrar a advertência de R. Connell (2005, p. 67-70) para o fato de que as masculinidades não são constructos compactos e monolíticos, quando chama a atenção para a possibilidade de contrariedades, contradições e crises, presentes no processo de percepção das masculinidades, enquanto categorias de gênero, culturalmente construídas. Nesse sentido, acredito que isto também ocorre com Ele, ao se dar conta de que, na verdade, o seu papel não era apenas o de personagem, mas de um narrador, protagonista de sua própria trajetória, um Eu, cuja crença na sua masculinidade como um bloco imutável acaba por cair por terra, num salutar reconhecimento da diferença.

Talvez essa seja a maneira encontrada para lidar com o fato de que, "mesmo sabendo que lhe falta algo, talvez uma peça do coração, nunca conseguiu definir a ausência que o abocanha para o cuspir logo de seguida" (GONÇALVES, 2006, p. 228). Essa também pode ter sido a razão de seu dinamismo em não conseguir se acomodar em desfechos confortáveis. Daí a mudança de foco narrativo de $3^{\text {a }}$ para a $1^{\text {a }}$ pessoa, porque a alteração primeira não deveria vir de fora, mas de dentro dele próprio, enquanto agente moldado pela autognose de um sujeito inserido em um contexto sociocultural.

Gosto de pensar, portanto, que o título desse romance de Hugo Gonçalves contém uma forte e sedutora ironia, porque se $O$ coração dos homens pode indicar um caminho puramente sentimental para a construção da trama, que, aliás, não ocorre, também não deixa de apostar em uma percepção das masculinidades, enquanto constructos heterogêneos e culturalmente constituídos, cujos agentes podem pressentir suas complexidades e contrariedades a partir de uma auto consciencialização, e não fugir delas. Antes, procuram aceitá-las como parte integrante de sua própria identidade.

Escrito e publicado há mais de 10 anos, O coração dos homens, de Hugo Gonçalves, constitui, assim, uma fábula absolutamente conectada com o nosso tempo. No mundo atual, onde as diferenças são observadas com discriminação e, muitas vezes, repudiadas com violência, o romance em foco torna-se uma leitura necessária e urgente, não para se repetir as mesmas situações efabuladas, mas para perceber que quaisquer atos de recusa, de rejeição e de extermínio do outro, pura e simplesmente por aquilo que ele/ ela é, não produzem qualquer tipo de benefício para as partes envolvidas.

Na verdade, não a entendo como uma obra apologética à violência, à brutalidade, à misoginia e/ou à homofobia, pelo contrário. Ao expor as fissuras e as fragilidades de masculinidades hegemônicas e motivadas por movimentos de ocupação e imposição colonizantes, Hugo Gonçalves chama a atenção para os perigos de repetições cíclicas e o prejuízo dos olhares descompromissados e dos gestos acomodatícios. 
Por outro lado, tal como o protagonista com os seus anseios, que sensivelmente percebe a imprescindibilidade das mutações, os desejos de mudança e de reconhecimento do outro precisam também ser sentidos a partir de cada indivíduo. Quem sabe, assim, o coração dos homens não seja tocado por uma sensibilidade capaz de os fazerem perceber que, ao contrário do que indicam as epígrafes de Joyce Carol Oates e Sugar Ray Seales, o amor comparece em primeiro lugar e a lucidez incita um exercício constante para se entender e se respeitar definitivamente "o sagrado direito à diferença" (MELO, 1982, p. 59).

\section{REFERÊNCIAS}

ALMEIDA, Miguel Vale de. Senhores de si. Uma interpretação antropológica da masculinidade. $2^{\text {a }}$ ed. Lisboa: Fim de Século, 2000.

AMANCIO, Lígia. Masculino e feminino: a construção social da diferença. Porto: Edições Afrontamento, 2010a.

O fim do sujeito universal. In: JOAQUIM, Teresa (org.). Masculinidades - Feminilidades. Porto: Edições Afrontamento, 2010b, p. 101-109.

CAMÕES, Luís de. Os Lusíadas. Edição organizada por Emanuel Paulo Ramos. Porto: Porto Editora, 2011.

CASCAIS, António Fernando. Masculinidades debaixo de fogo: homossociabilidade e homossexualidade na guerra colonial (1961-1974). Journal of Lusophone Studies, Washington, v. 4, no. 1, 2019, p. 134-159, 2019. Disponível em: https://jls.apsa.us/index.php/jls/article/view/302. Acesso em 09 de outubro de 2020.

CONNELL, R. W. Masculinities. Second Edition. Cambridge: Polity Press, 2005.

CONNELL, R. W.; MESSERSCHMIDT, J. W. Masculinidade hegemônica: repensando o conceito. Estudos feministas, Florianópolis, v. 21, no. 1, 2013, p. 241-281. Disponível em: https://periodicos.ufsc.br/index.php/ref/article/ view/S0104-026X2013000100014/24650 . Acesso em: 12 de abril de 2021.

GONÇALVES, Hugo. O coração dos homens. Lisboa: Oficina do Livro, 2006.

INÁCIO, Emerson da Cruz. Homossexualidade, homoerotismo e homossociabilidade: em torno de três conceitos e um exemplo. In: SANTOS, Rick; GARCIA, Wilton (org.). A escrita de adé: perspectivas teóricas dos estudos gays e lésbic@s no Brasil. São Paulo: Xamã: NCC/SUNY, 2002, p. 59-70.

LUGARINHO, Mário César. Masculinidade e colonialismo: em direção ao "homem novo" (subsídios para os estudos de gênero e para os estudos pós-coloniais no contexto de língua portuguesa. Abril - NEPA / UFF, Niterói, vol. 5, no. 10, p. 15- 38, abril de 2013. Disponível em: https://periodicos.uff. br/revistaabril/article/view/29682 Acesso em 02 de outubro de 2020. 
MAAS, Wilma Patrícia. O cânone mínimo. O Bildungsroman na história da literatura. São Paulo: Editora da UNESP, 2000.

MELO, Guilherme de. Ser homossexual em Portugal. Lisboa: Relógio d’Água, 1982.

SIMON, Luiz Carlos Santos. Fundamentos para pesquisas sobre masculinidades e literatura no Brasil. Revista Estação Literária, Londrina, v. 16, p. 8-28, jun. 2016. Disponível em: http://www.uel.br/revistas/uel/index.php/ estacaoliteraria/article/view/28472 Acesso em 13 de outubro de 2020.

Recebido para avaliação em 19/10/2020

Aprovado para publicação em 26/12/2020

\section{NOTAS}

1 Doutor em Letras Vernáculas (Literatura Portuguesa) pela Faculdade de Letras da UFRJ. Professor Associado do Departamento de Letras e Professor Permanente do Programa de Pós-Graduação em Estudos de Literatura da UFSCar. Coordenador do Grupo de Estudos Literários Portugueses e Africanos (GELPA/UFSCar). Vice-Presidente da ABRAPLIP $\square$ Gestões 2016/2017 e 2020/2021. https://orcid.org/0000-0002-9275-9801

2É preciso destacar que, anos mais tarde, a própria autora iria operar uma revisão dos conceitos articulados na obra de 1995 (CONNELL, MESSERSCHMIDT, 2013), em resposta a uma série de críticas colocadas a respeito da mesma. Ainda que tenha conhecimento deste ensaio mais recente, não me parece inadequado retomar algumas das suas concepções a fim de propor uma leitura do romance de Hugo Gonçalves, até porque, ao lado delas, as pertinentes e importantes reflexões de Almeida (2000) e Amâncio (2010a, 2010b) constituem um contributo coerente para a linha de análise pretendida.

3 Conceito articulado por Eve Kosofsky Sedgwick, em Between men: English literature and male homossocial desire (1985), e retomado diversas vezes pela crítica, a homossociabilidade é compreendida, aqui, como aquela "rede de relações, baseadas no patriarcado, que regulam o comportamento masculino de maneira a estabilizá-lo, hierarquiza-lo pela instauração de uma interdependência/solidariedade, para que ele seja sempre intermediado pelas barreiras do tipicamente masculino, constituídas como base de poder e de opressão de tudo o que não habita esse espaço, leia-se aqui não só as mulheres, como também homossexuais, crianças etc" (INÁCIO, 2002, p. 67). 